Journal of Economics and Behavioral Studies

Vol. 5, No. 9, pp. 573-579, Sep 2013 (ISSN: 2220-6140)

\title{
An analysis of Hotels and its Similarities to the Management of Hospitals: A case study of a Provincial Hospital in South Africa
}

\author{
A. Deen, ${ }^{*}$ R. Balkaran \\ Durban University of Technology, South Africa \\ *rishi@dut.ac.za
}

\begin{abstract}
The South African concept of Provincial Hospitals in South Africa is characterised by the fact that it is managed by the state and its structure, operations and location were predominantly influenced by its historical record and to a large extent the challenges experienced with its management is directly linked to the problems of the past. This specifically has to do with the dire lack of essential resources from financial aligned resources to health care expertise. The stand- off here is against the desperate need for basic health care services from the many millions that have been previously disadvantaged. The ability to close this gap lies in the heart of efficient, effective and economical management of the provincial hospitals. The management of hotels and its link to the management of hospitals becomes significant within this context as essential elements such as hospitality and hospitality practice may be embraced within the management of health care services within South Africa. The paper explores the strong theoretical base of hospitality within hotels and its relevance to hospitals which is premised on service delivery the roots of which are fixed on the efficiencies of management practice. A theoretical model will be explored in respect of its application to the management of provincial hospitals in South Africa. This is further enhanced by a parallel study of a provincial hospital in South Africa which would incorporate amongst other an analysis of its socio-economic and legislative environments.
\end{abstract}

Keywords: Hotels, Hospitals, Health Care, South Africa

\section{Introduction}

The public sector is under-resourced and over-used, whiles the growing private sector, run largely on commercial lines, caters to middle- and high-income earners who tend to be members of medical schemes, which are a small amount of the population, and to foreigners looking for top-quality surgical procedures at relatively affordable prices. The private sector also attracts most of the country's health professionals (South Africa Info, 2008). The government is under pressure servicing a large portion of the population who are not medical schemes within the public sector affecting the way service is delivered to the patients. Ntuli (n.d) agrees that the perilous growth of private healthcare providers in connection with the scarcity of resources, including finances and health personnel, inevitably affects access to health care for the majority of the population, and this is a phenomenon worthy of further examination from a human rights perspective. This implies that difficulties begin from top level management and travels through the system ultimately impacting the consumer, which are the patients.

Hospitality service and service delivery: Severt, Aiello, Elswick \& Cyr (2008) cited Lashley and Morrison (2000) that hospitality provides a commitment to meeting guests' needs as the primary focus in commercial operations through a host and guest relationship. The host and guest relationship is further characterized by hospitableness typically extended by the host to the guests then reciprocated by the guest to the host. Service is an intangible experience of performance that the guest or the customer receives along with the tangible side of the product purchased. Because of service, people are a part of the product and a good service team is essential. Ive (2000) identifies that to develop the highest standards of service, a deep understanding of guests' needs to be established, and further explains that it is the understanding the person or guest who is requiring the service - the customer - and how and why they need it - our product - in the first place.

Figure 1 identifies the applied approach to the guest cycle within the hospitality industry. The guest cycle represents the flow of business through a hotel identifying physical contacts, financial exchanges between guest and hotel. According Bardi (2011) guest hospitality begins at the arrival and registration process, as the front desk clerk begins the check-in process with a display of hospitality toward the guest, including eye contact and a warm smile. Bardi (2011) continues by emphasizing the importance of a warm 
welcome to a guest is essential, as it is expected with a high quality product and a well developed delivery system. Referring to Figure 1, Dix \& Baird (1998) agree the reason we care for our customers, is because we want them to come back, and once they have experience a product or service they have enjoyed, they will want to repeat it. Ford \& Heaton (2000) specify that the service encounter is the person to person interaction between the customer and the person delivering the service. Further acknowledges that the service encounter and interactions have critical moments within them which is of crucial importance to the guest's evaluation of service quality, and may make or break the entire guest experience. The service encounter may be demonstrated and actioned in Figure 1. Hence, Jones \& Lockwood (1989) support that any service encounter is of prime importance in determining the customer's overall satisfaction with experience and further explains this importance in his model of management influence on service.

Figure 1: Applied approach to the guest cycle Abbott \&Lewry (1999)

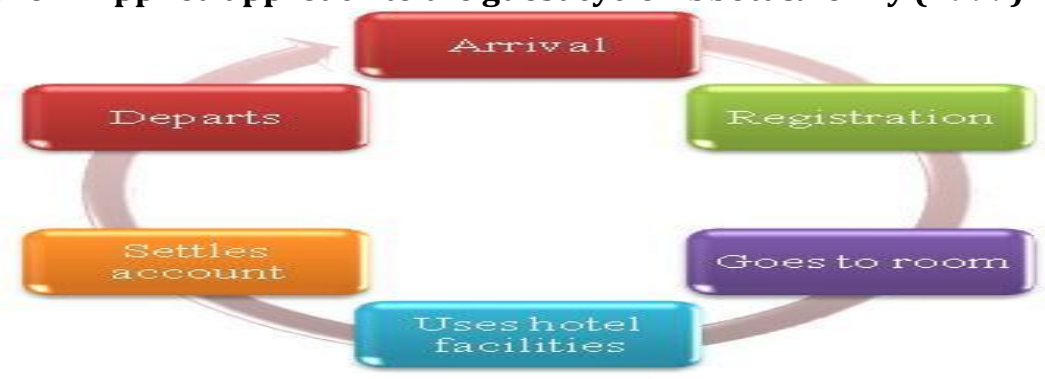

Figure 2: A model of management influence on service Jones \& Lockwood (1989)

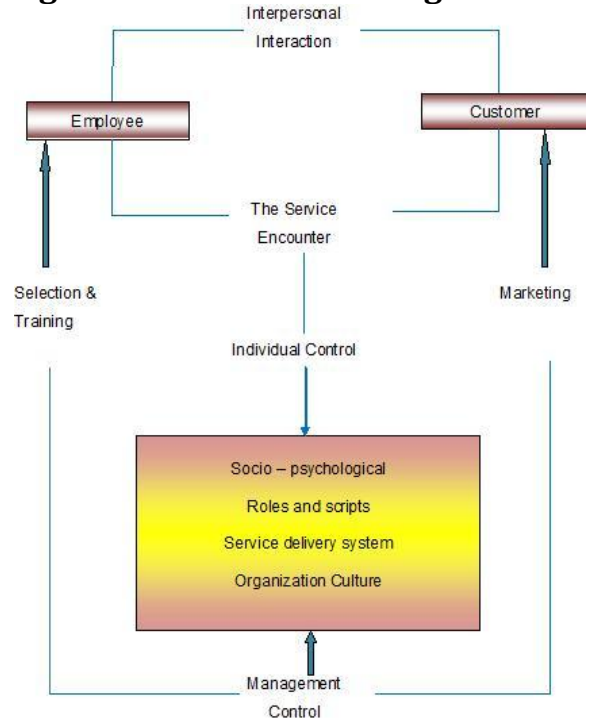

Figure 2 illustrates the influence that the manager has on service interaction and provides the framework for analyzing and discussing the effective management of service whereby Jones \& Lockwood (1989) believe that a manager needs to take a proactive approach to this encounter or experience. The model reveals that there is an interpersonal interaction between the employee and the customer, which creates the service encounter. The model also depicts that management control includes the selection and training process of the employee, which enhances the interpersonal action to the customer in terms of the quality of service, and marketing to the customer, which stimulates and creates the customer expectation. Olsen, Teare \& Gummesson (1996) support by stating the quality of the service rendered to external customers (guests) exhibited in Figure 1 (The applied guest cycle) depends on the quality of the service rendered to internal customers (staff). Essentially this requires that staff be seen as customers and their expectations understood, which can be identified in Figure 2, specifically referred to management control, their persuasion of staff, and therefore influencing the service encounter. With specific referenceFigures1 (The applied guest cycle) \& 2(The model of management influence) Bardi (2011) further supports that a hospitality manager needs to visualize the organization as dealing with the customer in terms of cycle of service, represented in Figure 1 (The applied guest cycle), a repeatable sequence of events in which various people try to meet the customer's needs and expectations at each point. 
Hospitality Management: Management is an integral part of the hospitality industry. According to David (2005) management is such an important element of the hotel industry that can make or spoil the industry and further defines it as a technique of getting things done through the efforts of others. Mullins (1999) states that management relates to all activities and at all levels of the organization and the overall responsibility of management can be seen as the attainment of the given objectives of the organization. Guests who frequent hotels expect procedures to be designed to enable a smooth flow of service, which is tailored to meet their individual needs. Keiser (1979) finds that industries where the product is service and tends to be handcrafted, management concerns itself with people. The hospitality industry is a people industry and Keiser (1979) points out that in a factory, the management deal with only with its employees as people; in retail establishment, the customers are the primary people concerned; whereas the hospitality industry is different, both employees and customers are dealt with at the same time. In the hospitality industry, employee commitment plays a major role in delivering a good customer experience, in turn leading to customer satisfaction; hence, employees must understand the importance of service and its relationship with the customer. Mullins (2001) outlines that the task of management is to make the use of staff, and the responsibility of management is to manage, however the efficiency of staff and their commitment to the aims and philosophy of the establishment are fostered by good human relationships and by the nature of managerial behaviour.

Williams \& Uysal (2003) concur that in any service industry the service role is basic and essential, and dependant on staff performance, and further explains that every employee who is in contact with external customers affects customer satisfaction. Berger \& Brownwell (2009) indicate that the hospitality industry is a high - contact setting that places physical, mental and emotional demands on employees. And Ford \& Heaton (2000: 110) support that managers of effective hospitality organizations understand the value of a strong culture and do whatever they can to reaffirm and support what the organization values, and if the culture supports excellent service, then the members learn that providing excellent service is what they supposed to do. Price \& Jaffe (2008) believe that service matters because customers who encounter bad service tell their friends and find other companies with which they would want to do business. In addition, in Figure 2 (The model of management influence), Jones \& Lockwood (1989) outline that a manager has direct control over influence through selection and training whereby influencing employee performance. Ford \& Heaton (2000) consolidates that service effectiveness depends on everyone throughout the organization taking service responsibility seriously and organizations need not hire anyone who is unwilling or unable to provide and deliver outstanding service. Jones \& Lockwood (1989) are in support of Ford \& Heaton's service effectiveness and Berger \&Brownwell's quality service concepts in his illustration and outlines that the manager does have influence over the role employee's play, the scripts they use, the design of the service delivery system, and the organization culture, which indirectly affect control over each interaction the employee is engaged in. Mullins (2001) justifies that the function that distinguishes the manager above all others is the function no one but the manager can perform, which is the ability to give others vision and the ability to perform, which is exhibited in Jones \& Lockwood's model in Figure 1. Furthermore, Walker \& Miller (2010) declare that if you want your people to treat guests courteously and serve them well, treat your associates courteously and well.

A Provincial Hospital in South Africa: According to Kandampully (2007), the national economy of every country depends on its service infrastructure including transport, communication, education, health care and various government entities. Hospitals are primarily for those who need in-patient care, although all have outpatients departments, casualty and emergency care. The Provincial Hospital is a District and Regional Hospital in line with the policy of the Provincial and National Departments of Health (Patient information booklet). It has 543 beds and located in Chatsworth, a suburb in the eThekwini health district (Chetty, 2009).During the apartheid era, there were huge inequities in the quality of care between hospitals in formerly black areas, and hospitals in urban areas to serve white patients. These inequalities still exist today. According to Melamed (2005), apartheid might have ended in 1994 but the struggle has not ended, it has merely changed its shape as new forms of community solidarity and resistance have emerged to fight for rights to housing, water and electricity, and workers' rights. Material inequality has deepened. In addition to the poverty and effects of post-apartheid, recession has also affected the community their culture as well as The Provincial Hospital itself.

KwaZulu Natal is seen as one of most densely populated out of South Africa's nine provinces and with the over population are serious challenges of poverty, illiteracy and poor infrastructure. These variables directly affect the Provincial Hospital, which are the contributing factors within the external environment. According to Chetty (2010), a patient should seek treatment at the preferred clinic in the area, and only 
once the patient receives a letter of referral then the next step should be a visit to the Provincial Hospital. The patient must be prepared to wait up to 8hours in the queue for treatment at the Provincial Hospital. The Provincial Hospital is designated a District and Regional hospital which therefore has to provide support to health workers in clinics the surrounding areas, provide community services, both in terms of clinical care and public health expertise. The Provincial Hospital has to also provide first level hospital care for the district and be the place of referral from clinics, community health centers in the southern region and be responsible for referring patients to higher levels of care when necessary (Chetty, 2009). This indicates that the Provincial may have limited facilities, however cannot turn patients away regardless of their limited capacity to treat all patients.

\section{Delivery of Service at the Provincial Hospital}

Figure 3: A flowchart depicting the patient process at the Provincial Hospital in South Africa (Unstructured interview Chetty, 2010)

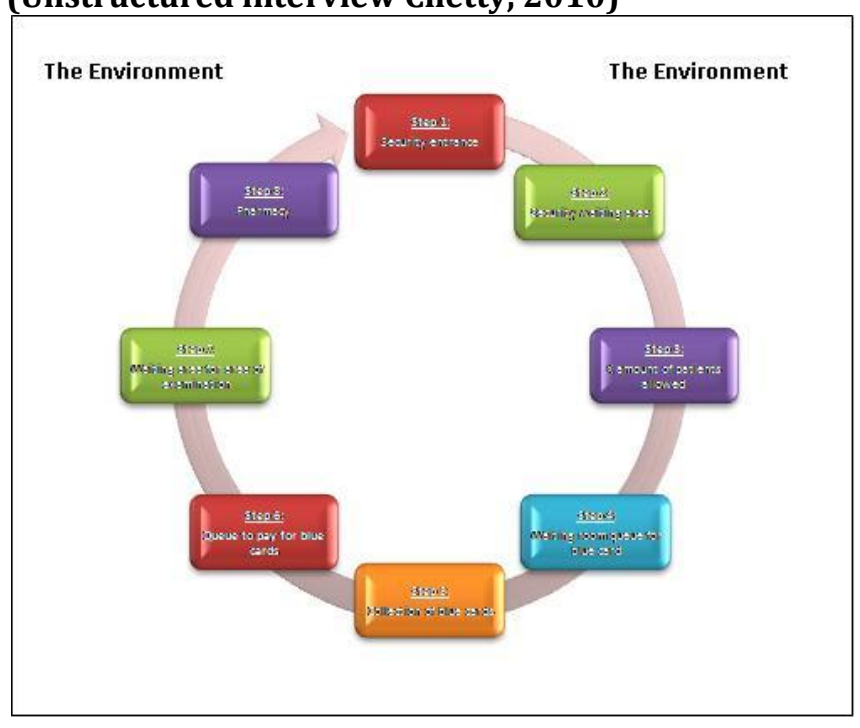

Figure 3 represents an applied flowchart depicting the process that patient experiences when treatment is sought at the Provincial Hospital similar to the applied guest cycle represented in Figure 1 . Figure 3 illustrates that there are 8 steps that a patient has to follow when seeking treatment. Figure 3 also includes the environment influenced by the economic climate of the Chatsworth area, the transport system and effects of post apartheid. Chetty (2010) outlines that a patient enters the Provincial Hospital at the security entrance and is directed by the security guards in to the waiting area of the Outpatients department. Thereafter the Security directs a certain number of patients at a time into the waiting room whereby patients queue in the waiting room for approximately an hour before proceeding on to their next step. The patients' start their day to seek treatment when they are sick. To have a regular check up with appointment or just to collect medication begins with long hours of waiting. This is tiresome for the patient or any human. Furthermore, when a patient is sick and waiting with others who are also ailing may promote further ailment. Patients then collect their respective blue cards. The blue card system assists the Provincial Hospital in tracking patients' activities. Unfortunately, an outdated system does not contribute to efficiency and effectiveness of the delivery of health care to the public. Once the blue cards are collected, they proceed to another queue to pay. Once the patient has paid for their blue card, the patient thereafter waits for treatment.

A patient may wait for approximately 2-3 hours depending on treatment and tests required. The final point of the patient process as illustrated in Figure 3whereby the patient collects their treatment from the pharmacy and then exits the hospital via Security. Figures 1 (The applied guest cycle) \& 3 (The patient process) show similarities in terms of the steps involved for physical contacts and financial exchanges at their respective organizations. According Srinivasan (2008) the needs of a patient can be identified within the following requirements:

- Attention: The patient requires immediate attention or at least the assurance that he would be attended to within a particular time frame.

- Information: The customers of hospital services require information about treatment, facilities and regular updates on patient's health and progress. 
- Listening: The patient, though unwell, has the deep desire to be listened to.

- Delivery of promised services: Expectations are built on promises. The customer must be given all that is promised and more.

All of the requirements are the common values that pilot service delivery within the hospitality industry and illustrated in Jones \& Lockwood's model of management in Figure 2.These values should be executed with the patient taking into consideration the interpersonal interactions of patient and hospital employee and ultimately the service encounter pointed out in the Jones \& Lockwood's model.

Figure 4: An applied model of management influence on patient service of the provincial hospital Jones \& Lockwood (1989)

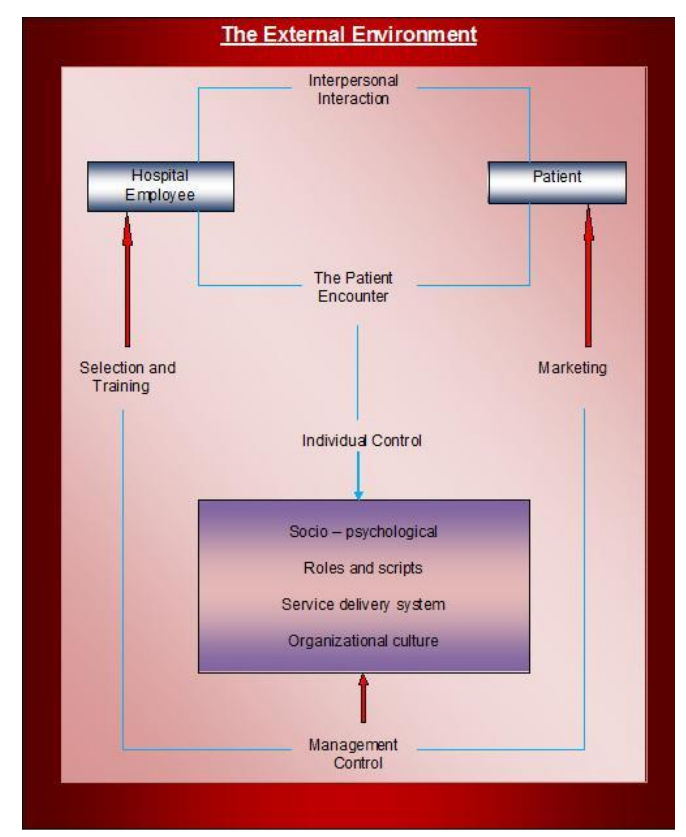

Figure 4 displays an applied model of Jones's approach to management influence on patient service within the Provincial Hospital. Similar to the model of Figure 1, Jones \& Lockwood (1989) illustrate the influence that the manager has influence on service within the interpersonal interaction. The applied model (Figure 4) was adapted for the Provincial Hospital involving hospital management and front-line employees for service quality improvement opportunities. This therefore provides the framework for analyzing and understanding the effective management of service whereby Jones depicts the service encounter between the employee and the customer. The applied model advances the service encounter as "patient encounter" between the hospital employee and the patient. This model may be applied to all customer-exposed departments within the Provincial Hospital together with its interdependent departments. Ultimately, Jones \& Lockwood advance that management control has influence in the manner in which employees perform. Hence, their psychological and social skills create an organizational culture, which promotes or demotes the manner an employee delivers service.

The Provincial Hospital may not be selling a leisure stay as do the hospitality industry, however the principles in the way that service is delivered behind both of these organizations are related and of vital importance to both customer and patient. Hence Jones \& Lockwood's applied model explains simply the necessary steps and the importance of management influence on staff and their attitude in their work, which is essential to both hospitality and health care. Soumya (2001) suggests that the most popular role of hospitality within the hospital sector are the supporting back of house areas and Singh (2006) proposes whether it's through the avenues of food and beverage or facility management, hospitals are outsourcing these vital components of their new business models to the players with core competencies in this field - the hospitality industry. However it is clear that this role extends further than the tangible similarities of these establishments. The result was in respect of the parallel fundamental systems within the hospitality and health care environment and they are encapsulated in the way these establishments both deliver their respective services offered. 
Hospitality and hospitals: Many medical facilities in hospitals are mimicking hotel environments. Singh (2006) certifies that hospitals are now taking the phrase 'being hospitable' to a new level, and believes who better to turn to than the hospitality industry itself for assistance. According to Singh (2006), the trend towards enhanced quality of services started when Dr Naresh Trehan, an executive director and chief cardiac surgeon, who worked in the US, came and returned to India in 1988, was keen on maintaining the standards he had witnessed and experienced in the US. All this meant a rigid clean and hygiene policy and exceptional F\&B guidelines. Fottler, Ford, Roberts, Ford \& Spears (2000) agree that over the last ten years the health care industry has recognized that the physical environment is a valuable resource that can affect all of its customers. Fottler et al. (2000) further highlight a significant statement that although most service organizations give some thought to setting, its importance to the service experience has been most thoroughly understood by those who view and treat their customers as guests, that is the guest service industry.

Hospitality is referred to as an industry that takes care of people who are away from their home and Mullins (1995: 9) confirms that efficient service and effective service delivery is paramount to a successful hospitality operation and customer satisfaction. Pienaar \& Willemse (2008) cite Hochschild (1983) with front-line service industry employees are confronted with extremely stressful and demanding situations, like putting on a smile while dealing with a demanding and insulting customerwhat is typically referred to as emotional labour. Pienaar \& Willemse further cite Pizam (2004) in his definition of emotional labour is associated with higher levels of perceived stress, distress and turnover, and lower levels of satisfaction in the service industries. In addition, in health care Du Toit et al. (2002) upholds the following:-

- Government institutions' obligation to deliver services efficiently, effectively and economically

- The public's legitimate right to receive efficient, effective and economic services

- The public's legitimate right to demand quality services if standards drop

Du Toit et al. (2002) states that it is the governments' responsibility to provide service to the public, which is effective, efficient, and value for money. In addition, the public are entitled to receive and demand quality services.

\section{Conclusion}

Efficiency becomes important if we take into consideration that the resources available to deliver services are far less than what the public demands in terms of service delivery. Because of the continuous shortage of resources, the efficiency and economy of government institutions and public officials is crucial. Apart from this, the public also expects efficiency, effectiveness and economy from government institutions and public servants Van der Walt \& Du Toit (1999). Hospitality is more than the extended service product that is provided by hotels and restaurants. It is evident that hospitality and hospitality management has its place within the health care environment, and it constitutes a significant role as it outlines the importance of efficient and effective service delivery and customer satisfaction represented in Jones's model of management influence in Figure 2.

\section{References}

Abbott, P. \& Lewry, S. (1999). Front Office: Procedures, Social Skills, Yield and Management. Oxford: Butterworth-Heinemann.

Bardi, J. A. (2011). Hotel Front Office Management. $4^{\text {th }}$ ed. Hoboken, N.J.: John Wiley \& Sons.

Berger, F. \& Brownwell, J. 2009. Organizational Behavior for the Hospitality Industry. Upper Saddle River, N.J.: Pearson Prentice Hall.

Chetty, K. (2009). RK Khan Hospital [online]. Available at: http://www.kznhealth.gov.za/rkkhanhospital.htm [Accessed 28 November 2009].

David, J. (2005). Textbook of Hotel Management. New Delhi: Anmol Publications.

Dix, C. \& Baird, C. (1998). Front Office Operations. Harlow, Essex: Longman.

Du-Toit, D., Knipe, A., Van-Niekerk, D., Van-der-Walt, G. \& Doyle, M. (2002). Service Excellence in Governance. Sandown: Heinemann Publishers.

Ford, C. \& Heaton, C. P. (2000). Managing the Guest Experience in Hospitality. Albany, N.Y.: Delmar/Thomson Learning. 
Fottler, M. D., Ford, R. C., Roberts, V., Ford, E. W. \& Spears, J. D. (2000). Creating a healing environment: The importance of the service setting in the New Consumer-Oriented Healthcare System [online]. Journal of Healthcare Management, 45(2), 91-106.

Ive, J. (2000). Achieving Excellence in Guest Service. Melbourne: Hospitality Press.

Jones, P. \& Lockwood, A. (1989). The Management of Hotel Operations. London: Cassell Educational.

Kandampully, J. A. (2007). Services Management: The New Paradigm of Hospitality. Upper Saddle River, N.J.: Pearson Prentice Hall.

Keiser, J. R. (1979). Principles and Practice of Management in the Hospitality Industry. Boston: CBI Publishing.

Melamed, Z. (2005). The struggle continues [online]. Available at: http://www.chatsworthlive.co.za/articles.php?step=2\&id=11 [Accessed 3 March 2010].

Mullins, L. J. (2001). Hospitality Management and Organisational Behaviour. Harlow, Essex: Longman.

Mullins, L. J. (1999). Management and Organizational Behavior. London: Pitman Publishing.

Mullins, L. J. (1995). Hospitality Management: A Human Resources Approach. Harlow, Essex: Longman.

Olsen, M. D., Teare, R. \& Gummesson, E. (1996). Service Quality in Hospitality Organizations. London: Cassell.

Pienaar, J. \& Willemse, S. A. (2008). Burnout, engagement, coping and general health of service employees in the hospitality industry [online].Tourism Management, 29(6), 1053-1063.

Price, B. \& Jaffe, D. (2008). The Best Service is No Service. San Francisco: Jossey-Bass.

Severt, D., Aiello, T., Elswick, S. \& Cyr, C. (2008). Hospitality in Hospitals? International Journal of Contemporary Hospitality Management, 20(6), 664-678.

Singh, P. K. (2006). Express Hospitality. Hospitals turn to Hospitality. Available at: http://www.expresshospitality.com/20060215/market01.shtml [Accessed 21 September 2011].

Soumya, V. (2001). RKHS: Making way for hospitality in hospitals. Available at: http://www.expresshealthcaremgmt.com/20010915/insignia2.htm [Accessed 22 March 2008].

South African Government Information: Health. (2008). Available at: http://www.info.gov.za/aboutsa/health.htm[Accessed 10 May 2009].

Srinivasan, A. V. (2008). Managing a Modern Hospital. Los Angeles, Calif.: Response Books.

Van der Walt, G. \& Du Toit, D. F. P. (1999). Managing for excellence in the public sector. $2^{\text {nd }}$ ed. Kenwyn: Juta.

Walker, J. R. \& Miller, J. E. (2010). Supervision in the Hospitality Industry, Leading Human Resources. Hoboken, N.J.: John Wiley \& Sons.

Williams, J. A. \& Uysal, M. (2003). Current Issues and Development in Hospitality and Tourism Satisfaction. Binghamton, N.Y.: Haworth Hospitality Press.

\section{UNSTRUCTURED INTERVIEWS}

Chetty, K. (2010). Interviewed by A. Deen. RK Khan Hospital, Durban, 30 March 